\title{
How to Promote Bluebirds in North Florida ${ }^{1}$
}

\author{
Holly K. Ober ${ }^{2}$
}

The Eastern Bluebird (Sialia sialis) is a thrush (Figure 1) that requires cavities for nesting. Bluebirds use naturally occurring cavities in trees, cavities hollowed out by woodpeckers, or artificial cavities provided by humans, such as birdhouses. Although the birds themselves are fairly common, the cavities they require are becoming rare, and bluebirds cannot excavate their own. You can help support these birds by supplying nesting habitat.

Bluebirds select nest sites in open, grassy areas. This is a setting where natural cavities are increasingly uncommon. If you choose to put out houses to create new nesting habitat for bluebirds, it is best to place them more than 50 feet from wooded or shrubby areas. This placement maximizes attractiveness to bluebirds while minimizing attractiveness to other cavity nesters (such as house wrens. Troglodytes aedon).

Bluebirds will nest in cavities located 2-20 feet off the ground. If you plan to provide a house, mounting it 4-6 feet off the ground is best because you can protect a house at this height from predators more easily than a house mounted lower. In addition, houses at this height are easier to monitor than those mounted higher. Attaching the house to a smooth metal or plastic pole with a small diameter is preferable to affixing it to a fencepost or a tree because the former is more difficult to climb and will thwart potential nest predators such as snakes, raccoons, and cats. Adding a baffle to your pole provides additional security for vulnerable eggs and chicks from climbing predators (Figure 2). Large-diameter baffles are most effective. Conical devices at least 24 inches in diameter or stovepipe baffles at least 8 inches in diameter work best.

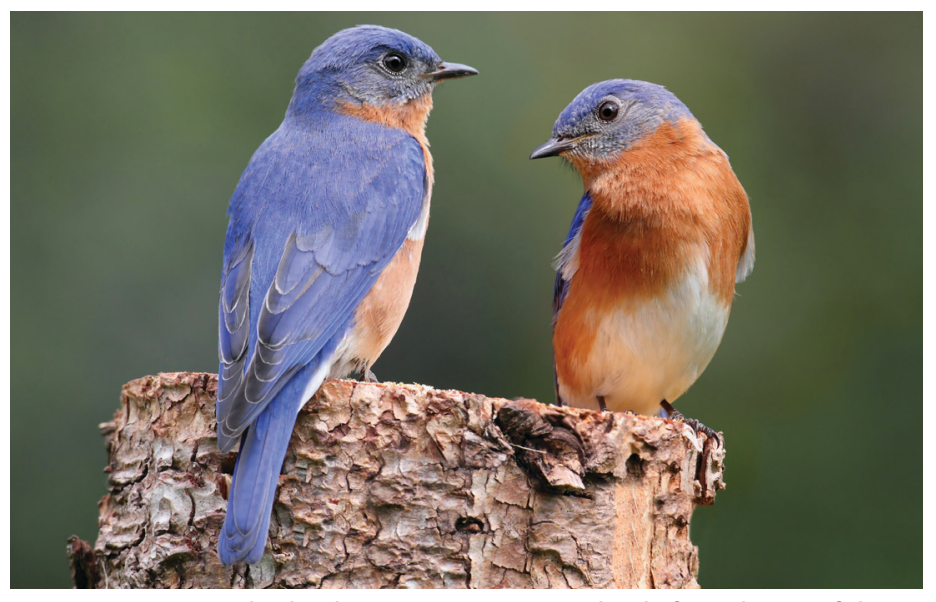

Figure 1. Eastern Bluebirds are cavity-nesting birds found east of the Rocky Mountains. Males are blue above with a rust-colored breast and white belly.

Credits: SteveByland/iStock/Getty Images Plus

Bluebirds create neat, cup-shaped nests 3-4 inches deep and 2-3 inches in interior diameter. Females weave pine needles and grasses into a cup shape and often line the interior with finer grasses and feathers (Figure 3). Females lay 2-7 eggs, which are $0.8 \times 0.6$ inches long. Eggs are typically light blue but sometimes white. Females then incubate the eggs for 2-3 weeks. Both parents feed the chicks, which gain feathers and begin to fly 2-3 weeks after hatching. Adult pairs often re-nest 2-3 times within a year in Florida.

A house that allows you to open the roof or side panel gives you access to the interior so that you can remove old nests each time chicks fledge and thoroughly clean the house at the end of each nesting season. Such access also allows you to monitor nesting activity periodically to document successful fledging and to identify problems. Don't disturb

1. This document is WEC406, one of a series of the Department of Wildlife Ecology and Conservation, UF/IFAS Extension. Original publication date March 2019. Visit the EDIS website at https://edis.ifas.ufl.edu for the currently supported version of this publication.

2. Holly K. Ober, associate professor and Extension specialist, Department of Wildlife Ecology and Conservation, UF/IFAS North Florida Research and Education Center, Quincy, FL 32351.

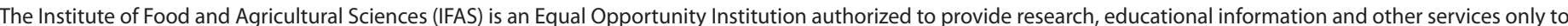

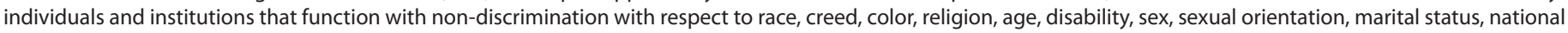
origin, political opinions or affiliations. For more information on obtaining other UF/IFAS Extension publications, contact your county's UF/IFAS Extension office. 
active nests too frequently: checking once per week is adequate to determine when chicks have fledged so that you can remove old nest material.

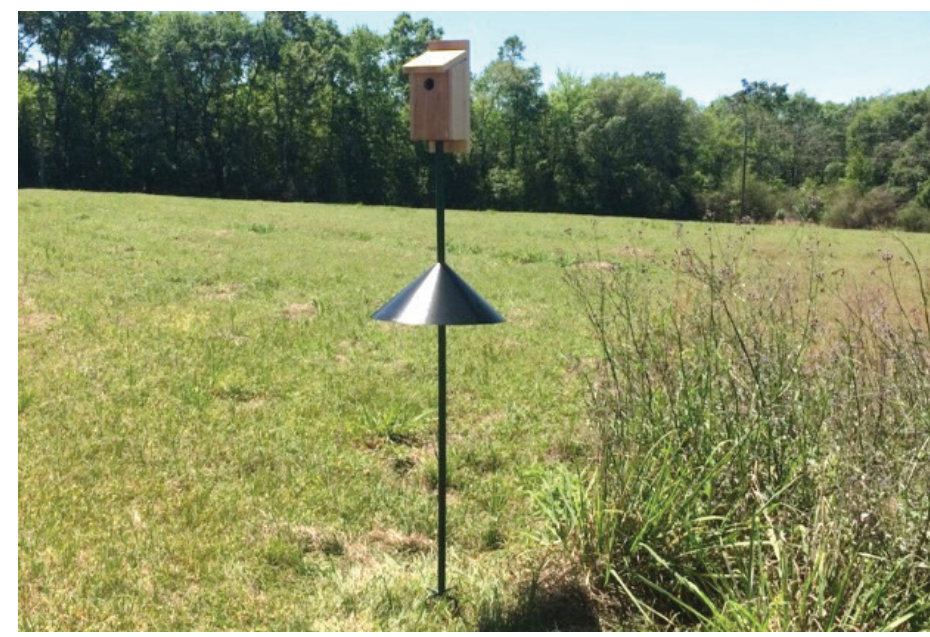

Figure 2. Bluebird houses should be located in open, grassy areas with no tall shrubs, at a height of 4-6 feet above the ground. To hinder access by predators, this $5 \times 5 \times 9$ " wooden house (commonly referred to as a "NABS-style house") is mounted on a smooth, thin pole equipped with a baffle.

Credits: Holly Ober, UF/IFAS

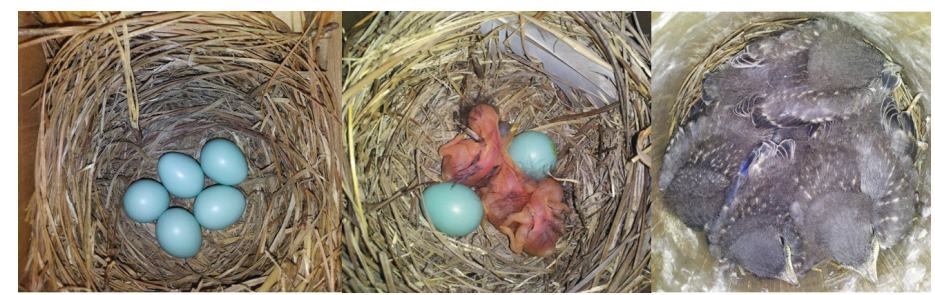

Figure 3. Pine needles are the primary material used to create nests. Females usually lay 3-6 eggs, which hatch within 2-3 weeks. Chicks fledge 2-3 weeks after hatching.

Credits: Sarah Friedl

Cavities are in high demand among songbirds. Other cavity-nesters that may compete with bluebirds for nesting locations in north Florida include the Carolina chickadee (Poecile carolinensis), the tufted titmouse (Baeolophus bicolor), the house wren, and the house sparrow (Passer domesticus). The materials these birds use to create their nests differ from the materials bluebirds favor, so your periodic nest checks could indicate that some other species of bird has used a house you intended for bluebirds. Carolina chickadees typically build a layered nest with a thick base of moss topped with a cup comprised of grass, fur, and feathers. They lay white eggs with reddish-brown spots. Tufted titmouse nests are made of a combination of moss, fur, and soft plant fibers, and their eggs are white with small red spots. House wrens create a layered nest with coarse twigs on the bottom and a cup with grass, feathers, and fur on top. They lay whitish-pink eggs with small red spots. House sparrows have a loose jumble of a wide variety of grasses, feathers, twigs, and even garbage. They lay cream-colored eggs with brown spots.
You can maximize your chances of attracting bluebirds to your houses by providing suitable housing in suitable locations. Below are suggestions.

\section{Recommendations}

\section{Choose a house with appropriate characteristics}

- Three general designs have been shown to work well for eastern bluebirds: a $5 \times 5 \times 9$-inch or $4 \times 4 \times 9$-inch wooden house (NABS style, Figure 2), a 4-inch-diameter cylindrical design made of PVC (Gilbertson style, Figure 4), and wooden triangular design (Peterson style, Figure 4).

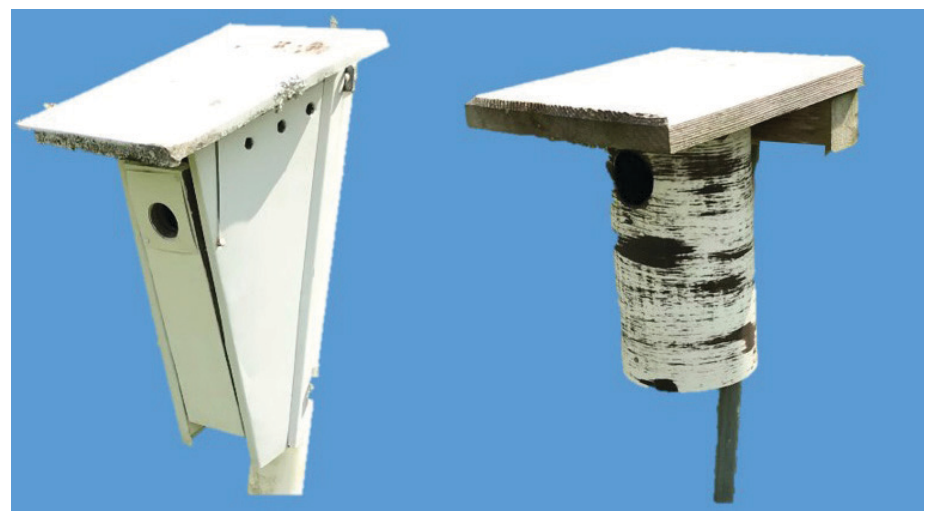

Figure 4. Bluebird housing tested in north Florida. Peterson (left) and Gilbertson (right).

- A 1.5-inch-diameter entrance hole allows access by bluebirds while preventing access by many other species. The entrance should be located 4 to 7 inches above the floor of the house.

- If your bluebird houses are made of wood, the wood should be untreated (do not use pressure-treated plywood because it could be toxic to birds).

- If you paint the exterior, choose a water-based latex paint because this type is non-toxic. White or some other light color is best to reflect the heat from sunlight. Do not paint the interior of the house.

- A large overhanging roof helps prevent rain from entering the entrance or ventilation holes. Consider a 2 -inch overhang on the sides and a 4 -inch overhang in the front.

- Ventilation holes help cool the house in the heat. Drill these holes at an upward angle so the shaft passes from a lower height on the exterior to a taller height on the interior to prevent rainwater from entering the house.

- Drainage holes in the floor can allow any rainwater that enters the house to drip out the bottom.

- A hinged front door, side panel, or top will facilitate cleaning and monitoring. 
- Bluebirds can easily enter and exit houses without a perch, whereas some non-native species need them to gain access. Therefore, perches should not be provided.

\section{Prevent predator access}

- Mount the house on a slim, smooth pole to limit access by climbing animals such as snakes, raccoons, and cats that could eat eggs or chicks. Avoid positioning houses on anything that could easily be climbed by predators, such as fence posts, utility poles, or trees.

- Add a baffle or a stovepipe-style guard, or grease the pole to further limit access by predators. The larger the diameter of the baffle, the more effective it will be at deterring predators.

\section{Choose an appropriate location}

- Locate the house in an open, grassy area (mowed lawn, field, meadow) with few trees and shrubs, so that birds will have plenty of space near the nest to forage on ground-dwelling insects.

- Locate boxes at least 100 meters (330 feet) apart from one another so that territorial birds don't prevent access by other bluebird pairs to nearby houses.

- Mount houses so that the base is 4 to 6 feet above the ground; if the base is higher, competition for the house by other bird species may increase; if it is lower, the house may be easily accessed by cats, raccoons, or snakes.

- Place houses at least 15 meters (50 feet) from brushy and heavily wooded areas, and orient the entrance away from bushes to prevent use by house wrens.

\section{Provide regular maintenance}

- Remove nests made by birds, wasps, or rodents before each bluebird nesting season begins (i.e., by the end of February each year).

- Clean old nest material from boxes after chicks fledge to encourage repeated nest attempts within a year.

- Make sure the pole on which the nest is mounted is set firmly in the ground and directly upright so that access is easy for birds yet difficult for predators.

- Check nests no more than once a week during the 2- to 3 -week period when females are incubating.

\section{Experiment to assess the preferences of birds in your} area

- If you have the space, try putting up more than one style of house to determine which the birds in your region prefer, and from which they fledge the greatest numbers of young. Consider the NABS, Peterson, and Gilbertson styles of houses.

- Try putting houses up in pairs with at least 100 meters (300 feet) between pairs of houses.

\section{Local Testing}

Over the course of a 5-year period, we tested two commercially available housing options to determine if one is more suitable for bluebirds than the other in north Florida: the Peterson house and the Gilbertson house (Figure 4). We established 8 pairs of houses, each consisting of one of each type of house separated by 5 meters (15 feet). Each pair of houses was an average of 250 meters ( 820 feet) away from the next closest pair.

We found that bluebirds used both types of houses and fledged chicks from each. Over the course of 5 years, bluebirds made 52 nest attempts in the Gilbertson houses and 33 nest attempts in the Peterson houses.

Although both types of houses were successful, birds preferred the Gilbertson houses. They laid an average of 5.4 eggs per year in these houses (214 eggs total over 5 years). In comparison, birds laid an average of 3.5 eggs per year in the Peterson houses (139 eggs total over 5 years).

We also found that bluebirds fledged more chicks in the Gilbertson houses. They fledged an average of 3.2 chicks per house (129 chicks total over 5 years). In comparison, the Peterson houses fledged an average of 1.5 chicks per house (60 chicks total over 5 years).

Clearly, both types of houses provide suitable conditions for bluebirds, and both can increase bluebird numbers by providing additional nesting habitat.

\section{Additional Information}

- Cornell Lab of Ornithology-Eastern Bluebird-Overview, Eastern Bluebird - Introduction

- Audubon Society-https://www.audubon.org/field-guide/ bird/eastern-bluebird

- Florida Bluebird Society-https://floridabluebirdsociety. org/ 